\title{
Metabolism and Distribution of Labeled Theophylline in the Pregnant Rat. Impairment of Theophylline Metabolism by Pregnancy and Absence of a Blood-Brain Barrier in the Fetus
}

\author{
MAURICE J. ARNAUD, ${ }^{(38)}$ INGRID BRACCO, AND CHRISTELLE WELSCH \\ Nestlé Research Department, CH-1814 La Tour-de-Peilz, Switzerland
}

\section{Summary}

Theophylline was shown to cross the placenta and to be distributed after $1 \mathrm{~h}$ among the organs of the fetus and the pregnant rat except for the brain. Lower radioactivity was found in the central nervous system of the pregnant rat compared to the other organs and particularly the brain of the fetus. The blood-brain barrier was observed for theophylline in the adult rat. The degree of exposure of the fetal brain is shown to be twice that of the adult brain. The total absence of a blood-brain barrier for the fetus is thus demonstrated. A ratio of brain to blood theophylline concentration of 0.40 and 0.87 was found respectively for the pregnant rat and the fetus. The presence of a blood-brain barrier observed in the rat cannot be extrapolated to the human. Either the absence or a less efficient blood-brain barrier in the human fetus and neonate has to be taken into consideration. After theophylline administration to pregnant asthmatic women, some of the neonates displayed clinical symptoms that may have been related to placental transfer of theophylline $(7,37)$.

The ability of rat fetus to methylate theophylline into caffeine is demonstrated. Traces of caffeine are produced in utero that may be explained by the absence of theophylline accumulation in the fetus.

Urinalysis of the metabolites showed that unchanged theophylline amounted to $73 \pm 6 \%$ of total urine radioactivity in the pregnant rat as compared to $35 \pm 3 \%$ in the non-pregnant animal. This impairment of theophylline metabolism in late pregnancy is explained by the decreased formation of 1,3-dimethyluric acid $(-68 \%)$. The production of 1-methyluric acid was less affected $(-30 \%)$. Modification of theophylline metabolism during human pregnancy has never been studied. Although 1,3-dimethyluric is the most important theophylline metabolite both in the rat and man, there are such important species differences in the quantitative metabolic pathways that it is important to show whether or not the results obtained from rat studies can be extrapolated to the human.

\section{Speculation}

In the human, the exposure of the fetus to impaired theophylline metabolism during pregnancy or the absence of a blood-brain barrier could explain clinical symptoms of neurotoxia observed in the neonate when theophylline was administered to pregnant women.

Theophylline has been shown to be effective in the treatment of adult patients with Cheyne-Stokes respiration since 1927 (35). It is now currently used in the control of neonate apnea (1). In 1978, Soyka and Neese (31) suggested that theophylline could be methylated into caffeine in treated children but their data did not exclude the exogenous origin of the caffeine observed. The phar- macokinetic profile of theophylline and caffeine, obtained recently (11) in preterm children whose intake of methylxanthines was controlled, showed that caffeine concentrations in the plasma increase during theophylline therapy and suggested that theophylline was methylated to caffeine. This observation was confirmed simultaneously by several groups $(8,12,13,28)$. However, a strict control of caffeine intake is very difficult in the human, as caffeine can be acquired transplacentally (18), from breast milk (11, 13), and from perfused blood (12) often used for these children. This caffeine can persist for a long time in the newborn (4 days half-life) (2) as compared with the nonsmoking adult (6 h half-life) (23).

Recently, using [ $\left.{ }^{3} \mathrm{H}\right]-\mathrm{S}$-adenosyl methionine, labeled caffeine was obtained from theophylline, in vitro, with human fetal liver homogenate (3). In vivo, $\left[{ }^{13} \mathrm{C}\right]$-caffeine was found in urine of preterm children fed $\left[{ }^{13} \mathrm{C}\right]$-theophylline $(14,15)$. From all these studies, the quantitative importance of theophylline methylation into caffeine is unknown both in utero and in the preterm children. There is also no data on the rat. The demonstration of the validity of the animal model is of importance to toxicologists.

In order to confirm the methylation of theophylline into caffeine in the animal model and to estimate its quantitative importance in utero, $\left[8-{ }^{14} \mathrm{C}\right]$ theophylline was administered orally to pregnant rats. Localization of radioactivity was studied by whole animal body autoradiography. Labeled compounds extracted from the placenta and fetus and excreted in the urine were separated and identified by thin layer chromatography and high pressure liquid chromatography. An increase of caffeine half-life was demonstrated in humans during late pregnancy $(24,27)$, which was probably linked with impaired caffeine metabolism. In this study, the urinary metabolites of theophylline were quantified and the metabolic pathway of theophylline in the pregnant rat was compared to those of the non-pregnant rat.

\section{MATERIALS AND METHODS}

$\left[8-{ }^{14} \mathrm{C}\right]-$ Theophylline (Amersham) was chromatographed on silica plates with the solvent systems 1/chloroform-methanol (4:1, v/v) and 2/chloroform-acetone-butan-1-ol-concentrated ammonium hydroxide (3:3:4:1, v/v). The absence of labeled caffeine and a radiochemical purity of theophylline higher than $99.5 \%$ was demonstrated (Radioscanner and Automatic Linear Analyzer, Berthold).

A dose of $4 \mathrm{mg} / \mathrm{kg}$ body weight of unlabeled theophylline, corresponding to $40-250 \mu \mathrm{Ci}$ was given by stomach tube to 15 control females Sprague Dawley rats and 20 pregnant rats at the 18 th day of gestation. The animals were housed in individual glass metabolic cages and were anesthesized $1 \mathrm{~h}(5$ controls and 5 pregnant rats), $7 \mathrm{~h}$ ( 5 controls and 6 pregnant rats), $48 \mathrm{~h}$ ( 5 controls and 3 pregnant rats), $72 \mathrm{~h}$ ( 3 pregnant rats) and $92 \mathrm{~h}$ ( 3 pregnant rats) after the administration. They were either frozen at $-70^{\circ} \mathrm{C}$ 
in an ethanol-dry ice bath (one pregnant rat at $7 \mathrm{~h}, 48 \mathrm{~h}$ and $96 \mathrm{~h}$ ) for whole animal body autoradiography (Leitz microtome) or autopsied to study the radioactivity present in the blood and organs of the rat, the fetus and the placenta. Urine excreted and ${ }^{14} \mathrm{CO}_{2}$ expired were collected and radioactivity determined by liquid scintillation counting (4). Total radioactivity in the feces, the organs of the rat, the placenta and the fetus, was counted after combustion (Oxymat, Intertechnique). Some organs were homogenized and ultrafiltrated (Amicon Centriflo ultrafilter) to identify the metabolites or extracted with dichloromethane to identify caffeine. Two dimensional chromatography of these extracts and urine samples was performed on silica plates $(0.25 \mathrm{~mm}$ thickness, Merck) with the solvent systems $1 /$ and 2/. The labeled compounds were localized by autoradiography (Kodirex, single coated film) and the peaks observed with radioactivity detectors were integrated (Le Croy 3500 computer). Urine was also analyzed by high pressure liquid chromatography using C-18 reverse phase column and $0.5 \%$ acetic acid with a gradient from $1.5-7.5 \%$ acetonitrile as eluent. The eluent was continuously analyzed in ultraviolet light ( $270 \mathrm{~nm}$, Uvikon) and for radioactivity (flow cell Berthold). The radioactive metabolites were quantified using a multichannel analyzer (Silena).

\section{RESULTS}

After oral theophylline administration, urinary excretion was the main elimination route. The kinetics were not significantly different for pregnant and non-pregnant rats. After $7 \mathrm{~h} 32 \pm 8 \%$ of the dose was recovered in the urine. The maximum elimination of $70 \pm 7 \%$ was reached after $24 \mathrm{~h}$. At that time only $1 \%$ of the dose was present in the organs. Fecal excretion amounted to $5 \pm$ $3 \%$ of the dose after $7 \mathrm{~h}$ and up to $18 \pm 2 \%$ after $24 \mathrm{~h}$. With the ring-labeled theophylline, the ${ }^{14} \mathrm{CO}_{2}$ collected corresponds to less than $0.3 \%$ after $7 \mathrm{~h}$ and showed a maximum expiration rate $10 \mathrm{~h}$ after oral administration to reach finally $6 \pm 1 \%$ of the dose.

Whole animal body autoradiography (Fig. 1) shows that $7 \mathrm{~h}$ after administration, the radioactivity spread to all parts of the animal and the fetus. The total radioactivity present in the placenta and the fetus $\mathrm{l}$ or $7 \mathrm{~h}$ after administration was extracted and chromatographed. Only labeled theophylline was detected which demonstrates its ability to cross the placenta. Accumulation of radioactivity was observed in the amnion. The blood-brain barrier of the pregnant rat seemed to prevent the passage of theophylline to the central nervous system. Figure 1 shows lower radioactivity into the maternal brain compared to other organs such as the liver, lung, muscle, kidney and spleen. However, theophylline could easily enter the brain of fetus. Three weighed samples of each organ $(100-400 \mathrm{mg})$ were combusted. The radioactivity was counted $(15,000-90,000 \mathrm{dpm})$ to compare the quantitative distribution of labeled theophylline. The results expressed as the ratio of radioactivity found in organs to blood of the pregnant rat are presented in Table 1. It shows that the radioactivity found in the

Table 1. Quantitative distribution of radioactivity in the organs of the pregnant rat and the fetus, $1 \mathrm{~h}$ and $7 \mathrm{~h}$ after oral theophylline administration ${ }^{1}$

\begin{tabular}{lcc}
\hline & \multicolumn{2}{c}{ Ratio } \\
\cline { 2 - 3 } & $\mathrm{I} \mathrm{h}$ & $7 \mathrm{~h}$ \\
\hline Pregnant rat $(n=6)$ & & \\
$\quad$ Brain & $0.41 \pm 0.01$ & $0.38 \pm 0.02$ \\
Spinal cord & $0.44 \pm 0.01$ & $0.41 \pm 0.06$ \\
Liver & $1.27 \pm 0.03$ & $1.15 \pm 0.03$ \\
Muscle & $0.92 \pm 0.02$ & $0.90 \pm 0.03$ \\
Lung & $1.09 \pm 0.01$ & $1.01 \pm 0.05$ \\
Spleen & $0.95 \pm 0.02$ & $0.94 \pm 0.03$ \\
Kidney & $1.49 \pm 0.07$ & $1.42 \pm 0.06$ \\
Heart & $1.03 \pm 0.01$ & $0.96 \pm 0.03$ \\
Fetus $(n=20)$ & & \\
Placenta & $0.99 \pm 0.01$ & $1.03 \pm 0.01$ \\
Brain & $0.87 \pm 0.02$ & $0.88 \pm 0.02$ \\
Liver & $1.01 \pm 0.03$ & $1.05 \pm 0.03$ \\
Blood & $0.84 \pm 0.02$ & $0.90 \pm 0.02$ \\
\hline
\end{tabular}

${ }^{1}$ The results are expressed as the mean ratio \pm S.E. of organ/blood radioactivity. Except for the liver and the kidney of the pregnant rat where theophylline metabolites can be detected, only labeled theophylline was observed in the other organs and the blood. For these organs, the ratio presented corresponds to theophylline concentrations in organs compared to those in the blood of the pregnant rat.

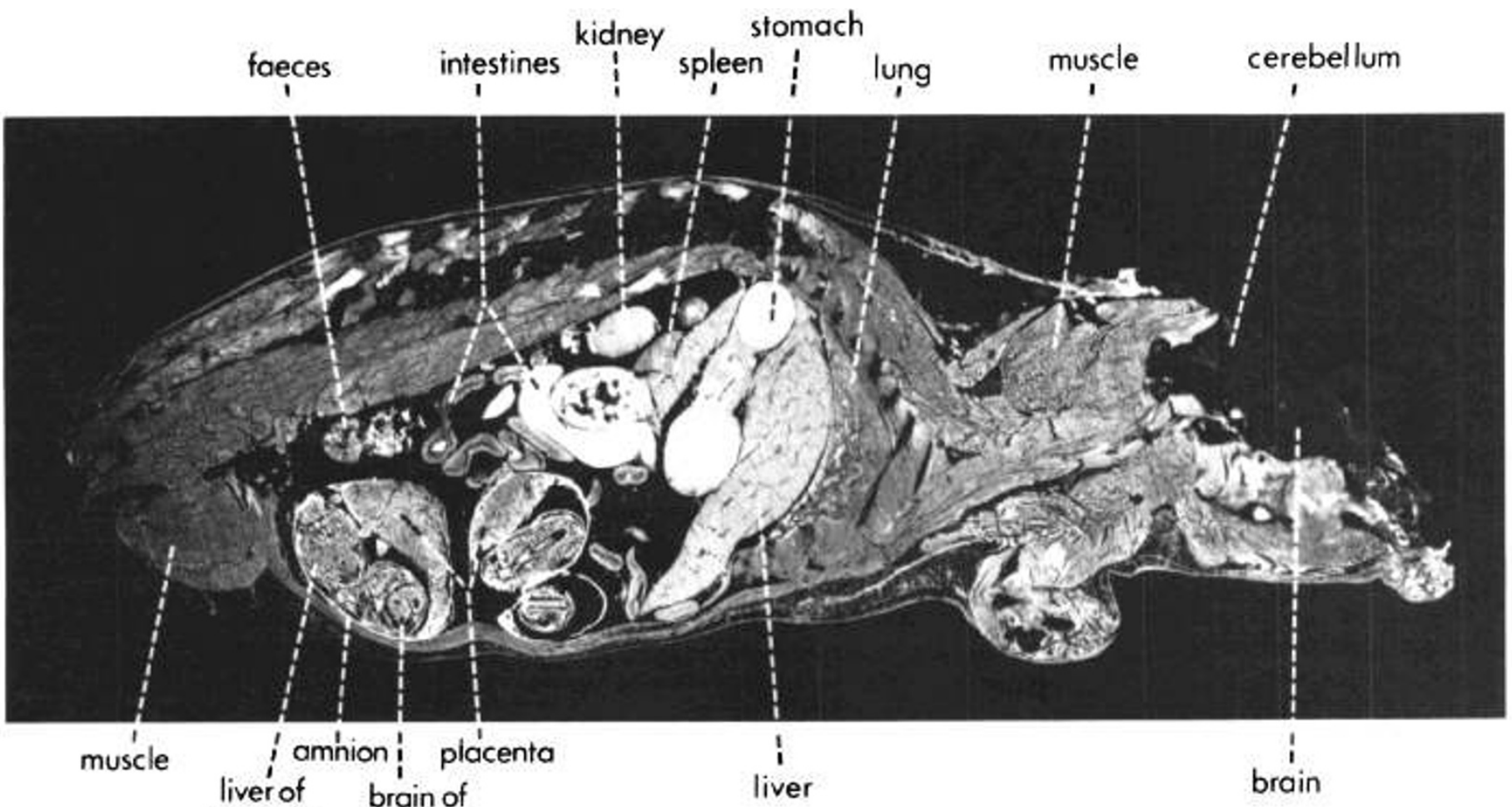

the fetus the fetus

Fig. 1. Whole animal body autoradiography of the pregnant rat, $7 \mathrm{~h}$ after the oral administration of $\left[8-{ }^{14} \mathrm{C}\right]$ theophylline. 
lung, the heart, the placenta and the liver of the fetus was in balance with the maternal blood radioactivity. A higher ratio was found in the liver and the kidney of the pregnant rat and is explained by the presence of significant amounts of theophylline metabolites. One and $7 \mathrm{~h}$ after the administration, lower amount of labeled theophylline were found in the muscle and the spleen of the pregnant rat; the brain and the blood of the fetus and particularly in the spinal cord and the brain of the pregnant rat. After $1 \mathrm{~h}, 7 \mathrm{~h}$ and also $48 \mathrm{~h}$, these ratios were not significantly changed and the concentration of theophylline in the brain of the fetus was twice as high as the concentration in the brain of the pregnant animal. Pregnancy did not affect the distribution of theophylline in the brain and the ratios were similar in the nonpregnant rats.

After 48 and $72 \mathrm{~h}$, the amount of radioactivity decreased not only in the organs of the pregnant rat but also in the placenta and the fetus. No accumulation of radioactivity was observed in the fetus. The highest concentration of labeled theophylline was found in the liver of the pregnant rat. After $92 \mathrm{~h}$, the radioactivity present in the fetus and the pregnant rat was too low to be seen by whole animal body autoradiography. Quantitative results showed that after 48 and $72 \mathrm{~h}$, total radioactivity found in the fetus corresponded to $0.6 \%$ and $0.1 \%$ of the administered dose. After $72 \mathrm{~h}$, the amniotic fluid contained $0.02 \%$ of the dose.

Quantitative urinary excretion of theophylline metabolites (Table 2) studied by high pressure liquid chromatography (Fig. 2) or thin layer chromatography showed that unchanged theophylline corresponds to $73 \pm 6 \%$ of urine radioactivity in the pregnant rat and only to $35 \pm 3 \%$ in the non-pregnant rat. This increased excretion of theophylline in the pregnant rat was mainly compensated by a decreased production $(-68 \%)$ of 1,3-dimethyluric acid (11 $\pm 5 \%$ in the pregnant rat and $34 \pm 2 \%$ in the non-pregnant rat). The production of 1 -methyluric acid, respectively $12.6 \pm 2 \%$ and $18 \pm 2 \%$ was less affected $(-30 \%)$. No changes could be shown for the minor metabolites: 3-methylxanthine, 1-methylxanthine, 3-methyluric acid and dimethylallantoin. No labeled caffeine or caffeine metabolites could be identified in the urine of the pregnant rat.

The ultrafiltrate of fetus homogenate was chromatographed with the solvent system $2 /$ where caffeine $\left(R_{F}, 0.73\right)$ was well separated from theophylline $\left(R_{F}, 0.19\right)$. Forty-eight $h$ after the administration, theophylline was the predominant compound present. Labeled caffeine was seen with a compound identified as a radioactive impurity found in the administered theophylline. Ninety-two $h$ after administration, more than 6 compounds were present in the fetus. Those present in the greatest amounts migrated close to caffeine with the solvent system $2 /$. Using twodimensional chromatography, a trace of caffeine was detected and separated from the major compound but two other minor compounds were shown to be close to caffeine. At that time, theophylline was not quantitatively the predominant compound in the fetus. These unidentified compounds, detected by very sensitive techniques after administration of a high dose of radioactivity $(250 \mu \mathrm{Ci})$, were not known as theophylline and caffeine metabo- lites. Also, none were identified as 1,3,9-trimethylxanthine, which could be produced by a nonspecific methylation of theophylline. The presence of labeled caffeine was also detected in dichloromethane extracts of placenta $48 \mathrm{~h}$ after the administration. Chro-

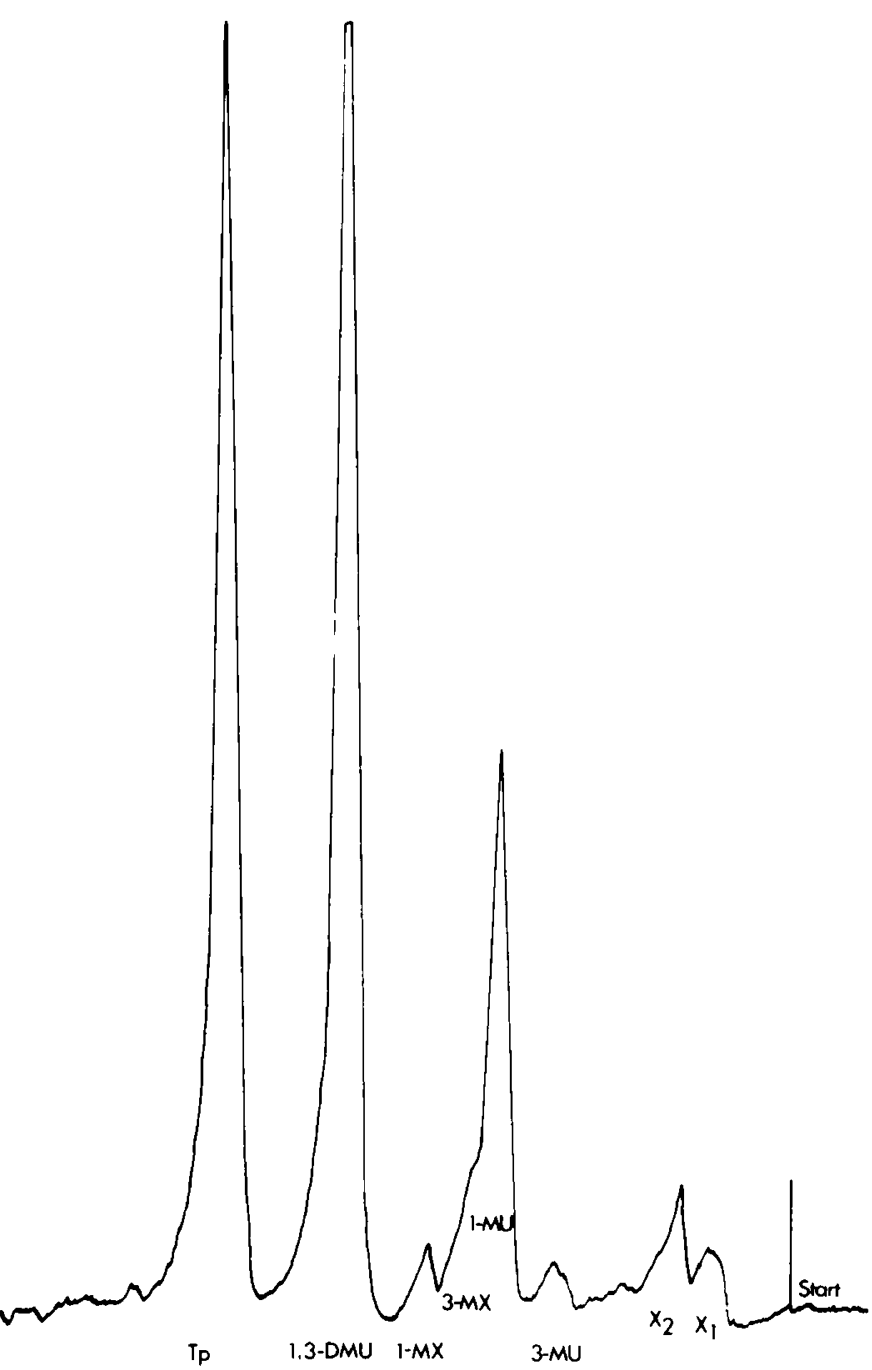

Fig. 2. Radioactivity profile of the separation of $\left[8-{ }^{14} \mathrm{C}\right]$ theophylline (Tp) metabolites obtained by high performance liquid chromatography on a C-18 reverse phase column. The eluent $(0.5 \%$ acetic acid with a gradient from $1.5 \%$ to $7.5 \%$ acetonitrile) was continuously flowed through a cell ( 50 $\mu$ ) filled with fine-grained glass scintillator (Berthold) and quantitative analysis of the radioactivity of the metabolites: 1,3-dimethyluric acid (1,3DMU), 1-methylxanthine (1-MX), 3-methylxanthine (3-MX), 1 methyluric acid (1-MU), 3-methyluric acid (3-MU) and two unknown polar compounds $\left(X_{2}\right.$ and $\left.X_{1}\right)$ were obtained with the integration of counts by multichannel analyzer (Silena).

Table 2. Theophylline metabolites excreted in the urine $(48 \mathrm{~h})$ of pregnant and non-pregnant rats expressed as \% of total urine radioactivity

\begin{tabular}{|c|c|c|c|c|c|c|}
\hline & \multirow[b]{2}{*}{$\begin{array}{l}\text { Recovery } \\
\% \text { of dose }\end{array}$} & \multirow[b]{2}{*}{1} & \multicolumn{4}{|c|}{ Metabolites } \\
\hline & & & $\begin{array}{l}\text { 1-Methyl } \\
\text { uric acid }\end{array}$ & $\begin{array}{l}\text { 1,3-Dimethyl } \\
\text { uric acid }\end{array}$ & $\begin{array}{l}\text { 3-Methyl } \\
\text { xanthine }\end{array}$ & Theophylline \\
\hline $\begin{array}{l}\text { Non-pregnant rats ( } n=5 \text {, high pressure } \\
\text { liquid chromatography }\end{array}$ & $70.0 \pm 7$ & $4.8 \pm 0.6$ & $18.0 \pm 2$ & $34 \pm 2$ & $3 \pm 1$ & $35 \pm 3$ \\
\hline $\begin{array}{l}\text { Pregnant rats ( } n=6 \text {, thin layer } \\
\text { chromatography) }\end{array}$ & $66.5 \pm 10$ & $0.6 \pm 0.5$ & $12.6 \pm 2$ & $11 \pm 5$ & $2 \pm 1$ & $73 \pm 6$ \\
\hline $\begin{array}{l}\text { Non-smoking men }{ }^{2} \text { ( } n=5 \text {, high pressure } \\
\text { liquid chromatography) }\end{array}$ & $80.0 \pm 6^{3}$ & & $26.0 \pm 6$ & $45 \pm 7$ & $9 \pm 2$ & $12 \pm 4$ \\
\hline
\end{tabular}

\footnotetext{
'Radioactivity identified as polar metabolites by HPLC and radioactivity at the origin of the chromatogram by thin layer chromatography.

${ }^{2}$ The quantitative metabolic pathway in man after oral theophylline administration at a dose of $4 \mathrm{mg} / \mathrm{kg}$ is added for comparison (6).

${ }^{3}$ With 1 -methylxanthine $(4 \pm 1 \%)$ and 3 -methyluric acid $(2 \pm 1 \%)$.
} 
matography of the amniotic fluid collected after $72 \mathrm{~h}$ contained only labeled theophylline.

\section{DISCUSSION}

Like caffeine, theophylline was shown to cross the placenta and to be distributed after $1 \mathrm{~h}$, among the organs of the fetus and the pregnant rat except for the brain. Four $h$ after the administration of caffeine, the maternal-fetal distribution in the brain was of the same order (21). On the contrary, with theophylline, our results demonstrated that lower radioactivity was found in the central nervous system of the pregnant rat compared to the other organs and particularly the brain of the fetus. The ratio between theophylline concentration in the blood of the fetus to blood of the pregnant rat was $0.84 \pm 0.02 \mathrm{I} \mathrm{h}$ after the administration, showing an effect of the placenta on theophylline distribution. Taking into account the ratio of $0.87 \pm 0.02$ between brain of the fetus to blood of the pregnant rat, the total absence of a blood-brain barrier for the fetus is thus demonstrated. The degree of exposure of the fetal brain is shown to be twice that of the adult brain. Theophylline accumulation in the brain of the rat neonate has been reported (22), but no data was available on the presence or absence of a blood-brain barrier for theophylline in the adult animal.

Results published by Thithapandha et al. (33) showed the distribution of theophylline and caffeine in the rat from 1-8 $\mathrm{h}$ after their intravenous injection $(36 \mathrm{mg} / \mathrm{kg})$. One $\mathrm{h}$ after injection, a ratio of 0.45 for brain to plasma theophylline concentration can be calculated from their results, in agreement with this study. However, after I h, there was not a parallel decrease of theophylline concentrations in brain and plasma, so that a ratio of 0.25 was reached after $7 \mathrm{~h}$. These authors observed a ratio close to 0.26 for caffeine, in disagreement with the study of Maickel and Snodgrass (21) and also with unpublished data obtained in our laboratory showing the absence of blood-brain barrier for caffeine. This low ratio can be explained by the inaccuracy of the extraction technique, which used no internal standard and substantiated by important variations observed for low tissue concentrations of caffeine. In contrast with the conclusion of Thithapandha et al., equimolecular doses of caffeine and theophylline certainly do not produce equal brain xanthine levels.

The comparative effects of theophylline and caffeine in vivo on rat's brain must be reanalyzed when the concentrations of methylxanthines are not studied. For example Berkowitz and Spector (10) conclude that theophylline was less potent than caffeine in elevating brain serotonin. Twice as much theophylline was necessary to elevate brainstem serotonin to the same level as caffeine. Our results demonstrate that this difference can be explained by the blood-brain barrier observed for theophylline in the adult rat and thus theophylline seems as potent as caffeine.

After an acute theophylline intoxication in an 1-month-old human infant (28) and in a 17 -month-old female (20), the ratio of theophylline concentration in the cerebrospinal fluid and the plasma was respectively from $0.60-0.63$ and 0.68 . This result is in agreement with the presence of a blood-brain barrier. In addition, a ratio close to 0.9 and of 0.88 for cerebrospinal fluid to serum in the neonate (34) and premature infant (30) have been reported. These results are both very close to our data from the animal model and tend to prove that there is, in the human, a maturation of this blood-brain barrier for theophylline. Caffeine produced by $\mathrm{N}-7$ methylation of theophylline in the 1-month-old infant (28) was found in the cerebrospinal fluid and in the serum with a ratio of concentrations close to 1 . These results of Simons et al. (28) are thus in agreement with the absence of a blood-brain barrier for caffeine. However no data on theophylline cerebrospinal fluid concentration in the adult human is available in the literature. The presence of a blood-brain barrier observed in the rat cannot be extrapolated to the human. Either the absence or a less efficient blood-brain barrier in the human fetus and neonate has to be taken into consideration because $0.4 \%-1.3 \%$ of pregnant women are asthmatic and after theophylline administration, some clinical symptoms in the neonate that may have been related to placental transfer of theophylline have been reported $(7,37)$. Most of the neurotoxic effects were observed in the case of neonates or children suffering from overdose (9). The few cases reported in the literature describing the effects on the neonate of theophylline administration to pregnant women are not sufficient to establish a relationship between the therapeutic dose of theophylline and the symptoms. More clinical observations need to be reported in this respect. In the animal, the study of the evolution of the bloodbrain barrier for theophylline from the fetus to the adult animal is underway in our laboratory.

Except in the kidney and the liver of the pregnant rat where the metabolites of theophylline can be detected and identified in the extracts [explaining a ratio (organ/blood radioactivity) higher than 1], it was very difficult to show the presence of labeled compounds other than theophylline in the other organs and the fetus. By increasing the dose of radioactivity administered, the presence of labeled caffeine was shown in the fetus and the placenta. The presence of other labeled compounds in the fetus are mainly explained by the radiochemical impurities of theophylline. The ability of rat fetus to methylate theophylline into caffeine is thus demonstrated. However, the absence of caffeine metabolites in the urine of the pregnant rat and the difficulty to detect caffeine in the fetus showed that only traces of caffeine are produced in utero. This minor production of caffeine can be explained by the absence of theophylline accumulation in the fetus. As shown by whole animal body autoradiography and the results of theophylline concentration in organs and blood, the elimination kinetics of theophylline from the fetus parallel that of the pregnant rat.

Until now, most of the in vivo experimental conditions showing the methylation of theophylline into caffeine have been restricted to preterm children. In such cases, theophylline given for the treatment of apnea exhibited a half-life 5-6 times longer than the adult half-life. The capacity of caffeine formation was thus increased. Caffeine produced tended to accumulate as its metabolism was reduced and caffeine half-life was longer compared to theophylline. Quantitative formation of caffeine from theophylline in preterm children is unknown and the use of $\left[{ }^{1.3} \mathrm{C}\right]$-theophylline should soon provide this information. In pregnant women, as the half-life of theophylline is unchanged (19), the fetal formation of caffeine must be reduced. However, only the use of $\left[{ }^{13} \mathrm{C}\right]$-theophylline and the study of urine excretion of $\left[{ }^{13} \mathrm{C}\right]-$ caffeine metabolites of the pregnant women can confirm this extrapolation of animal data.

Fecal excretion was relatively important with $18 \pm 2 \%$ of the administered dose and did not correspond to unabsorbed theophylline. Quantitative analyses were not performed but most of the radioactivity found in water extracts was identified as 1,3dimethyluric acid and 1-methyluric acid, showing that these metabolites were secreted by bile into the gastrointestinal tract. This is similar to another dimethylxanthine, theobromine (5). The kinetics of $\left[{ }^{14} \mathrm{CO}_{2}\right]$ expired from $\mathrm{C}-8$ labeled theophylline appeared to be also explained by the degradation of fecal metabolites by the intestinal flora. Thus for theophylline, about $1 / 4$ of the dose should be secreted into the bowels. However, the carbon 8 removal is not now an unexpected metabolic step as in the case of caffeine metabolism in the human where the removal of carbon 8 resulted in the formation of 5-acetylamino-6-amino-3-methyluracil (16).

Pregnancy did not affect the cumulative urinary excretion of theophylline and its metabolites in the rat. The results presented here are in agreement with previous published data obtained after intravenous injection (36).

In contrast with caffeine, which must be metabolized for its elimination, theophylline was shown in this study to be excreted unchanged very efficiently by the kidney of the pregnant rat, when the capacity for metabolism was reduced. This impairment of theophylline metabolism in late pregnancy has never been reported in the rat. The decreased formation of 1,3-dimethyluric acid, the most important metabolite of theophylline, is responsible of the increased excretion of unchanged theophylline. 
The urinary excretion of 1,3-dimethyluric acid was shown, in rats, to be increased by inducing agents like phenobarbital and 3methylcholanthrene while 1-methyluric acid excretion was increased only by 3 -methylcholanthrene (36). The ability of pregnancy to diminish production and excretion of this dimethyluric acid demonstrates that 8 -hydroxylation is certainly catalyzed by a different form of cytochrome than those involved in the formation of 3-methylxanthine and 1-methyluric acid. In the human, a similar conclusion was reached by Grygiel and Birkett (17) and Staib et al. (32) who demonstrated a metabolic shift in acute hepatitis and liver cirrhosis leading to a decreased excretion in the urine of 1,3-dimethyluric acid and 3-methylxanthine with a concomitant increase of 1 -methyluric acid excretion.

In the human, modification of theophylline metabolism during pregnancy has never been studied. Although 1,3-dimethyluric acid is the main theophylline metabolite both in rat and man, there are such large species differences in the quantitative metabolic pathways (Table 2) that it is important to show the effects of pregnancy on the quantitative theophylline metabolism and to know if the results obtained from the rat can be extrapolated to the human.

The prolonged caffeine half-life seemed to be linked with hormonal status and was reported in pregnant women $(24,27)$ baboons (29) and in users of steroid hormone contraceptives (25). On the contrary, a reduced theophylline half-life was observed in children treated with human growth hormone (26). These effects on the half-life must certainly reflect a decreased or increased capacity of metabolism. It is important to estimate during pregnancy not only the increased exposure of the fetus to the administered methylxanthine but also to know the pathways that are inhibited or induced because the metabolites produced can be transferred through the placenta to the fetus. In addition to fundamental studies on the animal model, extrapolation to human must be performed using molecules labeled with nonradioactive isotopes like $\left[{ }^{13} \mathrm{C}\right]$ and $\left[{ }^{15} \mathrm{~N}\right]$.

\section{REFERENCES AND NOTES}

1. Aranda. J. V. and Turmen. T.: Methylxanthines in apnea of prematurity. Clinics in Perinatology, 6: 87 (1979).

2. Aranda, J. V. Cook, C. E. Gorman, W. Collinge, J. M. Loughnan, P. M. Outerbridge, E. W.. Aldridge, A. and Neims, A. H.: Pharmacokinetic profile of caffeine in the premature newborn infant with apnea. J. Pediatr., 94: 663 (1979).

3. Aranda. J. V., Louridas, T., Vitullo, B. B., Thom, P.. Aldridge, A. and Haber, R.: Metabolism of theophylline to caffeine in human fetal liver. Science, 206: 1319 (1979).

4. Arnaud. M. J.: Identification. kinetic and quantitative study of $\left[2-{ }^{14} \mathrm{C}\right]$ and $[1-$ $\mathrm{Me}^{\left.{ }^{1+} \mathrm{C}\right]}$ caffeine metabolites in rat's urine by chromatographic separations. Biochem. Medic., 16: 67 (1976).

5. Arnaud. M. J. and Welsch. C.: Metabolic pathway of theobromine in the rat and identification of two new metabolites in human urine. J. Agr. Food Chem., 27: 524 (1979)

6. Arnaud, M. J. and Welsch. C.: Caffeine metabolism in human subjects. Proceeding of the IXth Int. Coll. on the Science and Technology of Coffee, June (1980).

7. Arwooc. L. L., Dasta. J. F. and Friedman, C.: Placental transfer of theophylline: two case reports. Pediatrics, 63: 844 (1979).

8. Bada. H. S., Khanna. N. N.. Somani. S. M. and Tin, A. A.: Interconversion of theophylline and caffeine in newborn infants. J. Pediatr.. 94: 993 (1979).

9. Begue, P. and Lasfargues, G.: Accidents neurologiques de la theophylline et de la piperazine. Rev. Prat., 20:5319 (1970).

10. Berkowitz. B. A. and Spector. S.: The effect of caffeine and theophylline on the disposition of brain serotonin in the rat. European J. Pharm., 16: 322 (1971).

11. Bory, C. Baltassat, P., Porthault, M., Bethenod, M., Frederich, A. and Aranda, J. V.: Metabolism of theophylline to caffeine in premature newborn infants. J.
Pediatr. 94: 888 (1979)

12. Boutroy, M. J., Vert, P.. Royer, R. T., Monin, P. and Royer-Morrot, M. J.: Caffeine, a metabolite of theophylline during the treatment of apnea in the premature infant. J. Pediatr., 94: 996 (1979).

13. Brazier, J. L., Renaud. H., Ribon. B. and Salle. B. L.: Plasma xanthine levels in low birth weight infants treated or not treated with theophylline. Arch. Disease in Child., 54: 194 (1979).

14. Brazier. J. L., Ribon. B., Desage. M. and Salle. B.: Study of theophylline metabolism in premature human newborns using stable isotope labelling. Biomed. Mass Spectrometry, 7: 189 (1980).

15. Brazier. J. L.. Salle. B., Ribon, B., Desage, M. and Renaud. H.: In vivo Ni methylation of the theophylline to caffeine in premature infants. Studies with use of stable isotopes. Develop. Pharm. and Ther., 2: 137 (1981).

16. Callahan. M. M., Roberston, R., Branfman. A. R., McComish, M. and Yesair, D. W.: Human metabolism of radiolabeled caffeine following oral administration. Proceeding of the IXth Int. Coll. on the Science and Technology of Coffee, June (1980).

17. Grygiel, J. J. and Birkett. D. J.: Effect of age on patterns of theophylline metabolism. Clin. Pharm. Ther.. 28: 456 (1980).

18. Horning, M. G., Butler, C. M.. Nowlin. J. and Hill, R. M.: Drug metabolism in the human neonate. Life Sci., /6: 65I (1975).

19. Jusko, W. J., Gardner, M. J., Mangione, A., Schentag, J. J., Koup, J. R. and Vance, J. W.: Factors affecting theophylline clearances: age, tobacco, marijuana, cirrhosis, congestive heart failure, obesity, oral contraceptives, benzodiazepines, barbiturates and ethanol. J. Pharm. Sci., 68: 1358 (1979).

20. Kadlec, G. J., Jarboe. C. H.. Pollard. S. J. and Sublett. J. L.: Acute theophylline intoxication. Biphasic first order elimination kinetics in a child. Annals of Allergy, 41: 337 (1978).

21. Maickel, R. P. and Snodgrass. W. R.: Physicochemical factors in maternal-fetal distribution of drugs. Toxicol. Appl. Pharmacol., 26: 218 (1973).

22. Neese, A. L. and Soyka, L. F.: Toxicity and tissue distribution of aminophylline in neonatal and adult mice and rats. Pediatr. Res., 11: 783 (1977).

23. Parsons. W. D. and Neims, A. H.: Effect of smoking on caffeine clearance. Clin Pharmacol. Ther., 24: 40 (1978)

24. Parsons. W. D., Pelletier, J. G. and Neims, A. H.: Caffeine elimination in pregnancy. Clinical Res.. 24: 652A (1976).

25. Patwardhan. R. V.. Desmond. P. V.. Johnson. R. F. and Schenker. S.: Impaired elimination of caffeine by oral contraceptive steroids. J. Lab. Clin. Med., 95 603 (1980).

26. Redmond, G. P., Bell, J. J., Nichola, P. S. and Perel, J. M.: Effect of growth hormone on human drug metabolism: time course and substrate specificity. Pediatric Pharm., 1: 63 (1980).

27. Rothweiler. H., Knutti, R. and Schlatter, Ch.: Einfluss von Schwangerschaft und Geschlecht auf die individuelle Variation des Koffeinabbaus. Mitt. Gebiete Lebensm. Hyg.. 72: 88 (1981).

28. Simons. F. E.. Friesen. F. R. and Simons, K. J.: Theophylline toxicity in term infants. Am. J. Dis. Child., 134: 39 (1980).

29. Ray Kling, O. and Dix Christensen. H.: Caffeine elimination in late pregnancy. Fed. Proceedings, 38: 266 (1979).

30. Somani. S. M.. Khanna. N. N. and Bada. H. S.: Caffeine and theophylline serum/CSF correlation in premature infants. J. of Pediatr., 96: 1091 (1980)

31. Soyka, L. F. and Neese, A. L.: Perinatal exposure to methylxanthines: possible effects on pregnancy outcome. Clin. Pharmacol. Ther., 23: 130 (1978).

32. Staib, A. H., Schuppan. D., Lissner. R. Zilly, W., v. Bomhard, G. and Richter. E.: Pharmacokinetics and metabolism of theophylline in patients with liver diseases. Int. J. of Clinical Pharm.. Therapy and Toxicol., I8: 500 (1980).

33. Thithapandha, A., Maling, H. M. and Gilette, J. R.: Effects of caffeine and theophylline on activity of rats in relation to brain xanthine concentrations. Proc. Soc. Exp. Biol. Med. 139: 582 (1972).

34. Tin, A. A., Somani, S. M., Bada, H. S. and Khanna. N. N.: Caffeine, theophylline and theobromine determinations in serum, saliva and spinal fluid. J. of Anal. Toxicol.. 3: 26 (1979).

35. Vogl, A: Euphylline. Wien Klin. Wochenschr., 40: 105 (1927).

36. Williams, J. F., Lowitt, S. and Szentivanyi, A.: Effect of phenobarbital and 3methylcholanthrene pretreatment on the plasma half-life and urinary excretion profile of theophylline and its metabolites in rats. Biochem. Pharm., 28: 2935 (1979).

37. Yeh, T. F. and Pildes, R. S.: Transplacental aminophylline toxicity in a neonate. Lancet, 1: 910 (1977).

38. Requests for reprints should be addressed to: Dr. M. J. Arnaud, Research Department. Nestle Products Technical Assistance Co. Lid., CH-1814 La Tourde-Peilz, Switzerland.

39. Received for publication December 5, 1979

40. Accepted for publication October 6, 1981. 